\title{
Surgical Pathology Report
}

National Cancer Institute

\section{Source}

National Cancer Institute. Surgical Pathology Report. NCI Thesaurus. Code C45260.

A pathology report based upon samples obtained by or during surgery. 